\title{
DIÁLOGO ENTRE GEOGRAFIA E TEOLOGIA: CONSTRUÇÃO DE UM NOVO LUGAR, A EXPERIÊNCIA DE VIGOLO (NOVA TRENTO)
}

\begin{abstract}
Tarcísio Justino Loro ${ }^{1}$
Resumo: Este trabalho surgiu de uma reflexão interdisciplinar. De um lado a reflexão teológica e do outro a geografia humana. Desejamos a partir de uma visão cultural do espaço e da reflexão teológica mostrar o quanto estas duas ciências, teologia e geografia, podem se associar na organização do espaço social. Partimos do pressuposto suficientemente explorado de que o espaço geográfico é produzido a partir de diversos interesses, dentre eles, econômico, político, esportivo, educacional, cultural e o religioso. Neste encontramos também, sem dúvida, além dos mesmos interesses, o específico da religiosidade. Geografia e teologia dialogam na reorganização do novo espaço em Vigolo, Nova Trento. A cultura religiosa, tendo como cenário a vida de Madre Paulina, foi se firmando e abrindo espaço para uma nova função espacial. A fim de acolher as novas exigências do despertar da fé em Santa Paulina, muitas transformações ocorreram nos lugares onde viveu, trabalhou e fundou sua comunidade religiosa. A religiosidade popular de Vigolo passa a ter como centro a vida e obra de Madre Paulina, e sua santificação Ihe garante o estatuto para realizar no espaço da Vila Vigolo tudo o que for necessário para despertar ainda mais a devoção à primeira Santa Brasileira. Novas formas com novos conteúdos para receber os peregrinos e também os turistas, um novo espaço com outras funções.
\end{abstract}

PALAVRAS CHAVES: Geografia, Teologia, Madre Paulina, Reconstrução de Vigolo.

\section{DIALOGUE BETWEEN GEOGRAPHY AND THEOLOGY: A NEW PLACE BUILDING, A VIGOLO EXPERIENCE (NOVA TRENTO)}

\begin{abstract}
This paper came out from an interdisciplinary reflection. At one side the pastoral theological reflection and at the other, human geography. From another standpoint we wish to reflect and to show how much these two sciences, theology and geography, can contaminate each other in the creation and organization of the social space. We start from the sufficiently explored assumption that the social space is created based on different interests, economical, political, sportive, educational and cultural among others. And why not religious? In the social space we undoubtedly find, besides those same interests, the one related to religiosity. Geography and theology dialogue in the reorganization of the new space at Vigolo, Nova Trento. Religious culture, having Madre Paulina's life as background, got steadier and opened space for a spatial reorganization. In order to accommodate the new exigencies of the awakening of faith in Saint Paulina, many transformations occurred in the places where she lived, worked and founded her religious community. A popular religiosity at Vigolo starts having Madre Paulina's life and labour as its centre and her sanctification provides the charter to make at Vila Vigolo everything that is necessary to grow even more the devotion to the first Brazilian Saint.
\end{abstract}

KEY WORDS: Geography, Theology, Madre Paulina, Reconstruction of the Vigolo.

1. Doutor em Teologia. Professor do Centro Universitário Nossa Senhora da Assunção e da PUC. (tarjuslo@terra.com.br). 


\section{INTRODUÇÃO}

Tem sido grande o esforço dos geógrafos que buscam o diálogo interdisciplinar. Existem dificuldades como em qualquer campo científico. Neste caso, oriundas da tradição positivista e da visão marxista do espaço e da forte tendência ecológica, apesar disso, a busca de diálogo continua. Esses obstáculos têm dificultado a desejada afirmação da geografia como ciência social. As tendências de uma geografia humanista nesses últimos anos estão reafirmando esse diálogo.

É neste contexto de abertura e de "crise" diante das questões da sociedade, que a geografia começa a se interessar cada vez mais, pela manifestação da religiosidade ou da religião na produção do espaço geográfico. Desta forma, paulatinamente, a linguagem teológica ou as expressões religiosas passam a fazer parte do estudo geográfico, como ideologia ou como instituição, ou como um fenômeno que produz, cria e renova o espaço social.

Este trabalho surgiu de uma reflexão interdisciplinar. De um lado a reflexão teológica e de outro a geografia humanista. Aparentemente são dois campos que não apresentam congruências, ou pontos de intersecção. Por outro lado, desejamos refletir e mostrar o quanto estes dois conhecimentos geografia e teologia, podem se associar na organização do espaço social. Partimos do pressuposto suficientemente explorado de que o espaço social é produzido a partir de diversos interesses, dentre eles, econômico, político, esportivo, educacional e cultural. E também religioso? Neste encontramos também, sem dúvida, além dos mesmos interesses, o específico da religiosidade.

Olhando o tema relacional geografia e teologia, verificamos nas páginas da Bíblia a necessidade da conquista de uma terra ou território que está marcado pela iniciativa, proteção e promessa divinas o que amplia a ideologia de que Deus se preocupa com a prosperidade, a liberdade e a formação de um povo. Neste sentido, gostaríamos de recordar a figura paradigmática do hebreu Abraão que a mando de Deus deixou tudo para se colocar a caminho em vista da conquista da nova terra - "Sai da tua terra, da tua parentela e da casa de teu pai, para a terra que te mostrarei" $(G n 12,1)$. Deus inaugura uma nova pedagogia de sua revelação para os homens de todos os tempos, a necessidade de se colocar a caminho, a fim de construir novos lugares. Aqui, certamente, está a raiz das peregrinações aos lugares marcados pelo sagrado. Raiz do turismo religioso. 
Com sua atitude, Abraão instaura um novo paradigma de vida para o homem crente: levantar, partir e conquistar; a desinstalação por causa da fé é o novo paradigma que está presente em toda história da vida do povo eleito, "Israel partiu com tudo o que the pertencia" (Gn 46,1). Moisés em obediência a Yahweh, ao apresentar-se perante o Faraó, pede-lhe para deixar seu povo partir a fim de prestar culto ao seu Deus, não em território egípcio, mas na terra prometida. (Cf. Ex 5,1). O êxodo é o acontecimento fundante de uma visão de território. Este se torna símbolo do "espaço" celeste que deve ser a conquista de todo ser humano.

Mais modernamente, podemos dizer que os santuários são de alguma forma a conquista de um lugar, a afirmação de uma ideologia, a concretização da esperança e o lugar onde Deus parece estar mais pronto e próximo para escutar seu povo.

Os santuários são um tema de estudo com interesse geográfico e podem ser analisados em termos monográficos ou em uma escala que transcende o local. Os lugares são essa materialização de que o sagrado necessita para se tornar visível aos olhos dos crentes e é daqui que resulta a sua atratividade especificamente religiosa, independentemente e para além de quaisquer outras funções que possam também exercer. ${ }^{2}$

Também no Novo testamento, determinados lugares são marcados pela presença do sagrado e, por isso, atraem peregrinações. Jesus com seus pais e parentes partia todos os anos em peregrinação ao templo de Jerusalém, por ocasião da festa da Páscoa. (Cf. Lc 2,41). Jerusalém acolhe, simboliza e se torna ícone da história da salvação. Tudo fala da experiência de fé do povo hebreu, inclusive a destruição do templo e a conservação dos grandes marcos de fé.

O velho paradigma se renova em nova realidade: fontes do imaginário religioso de Vigolo.

2. ROSENTHAL Z. e CORREA, Roberto L. (org), Manifestações da Cultura no Espaço. Rio de Janeiro: Ed. UERJ, 1999, p. 82. 


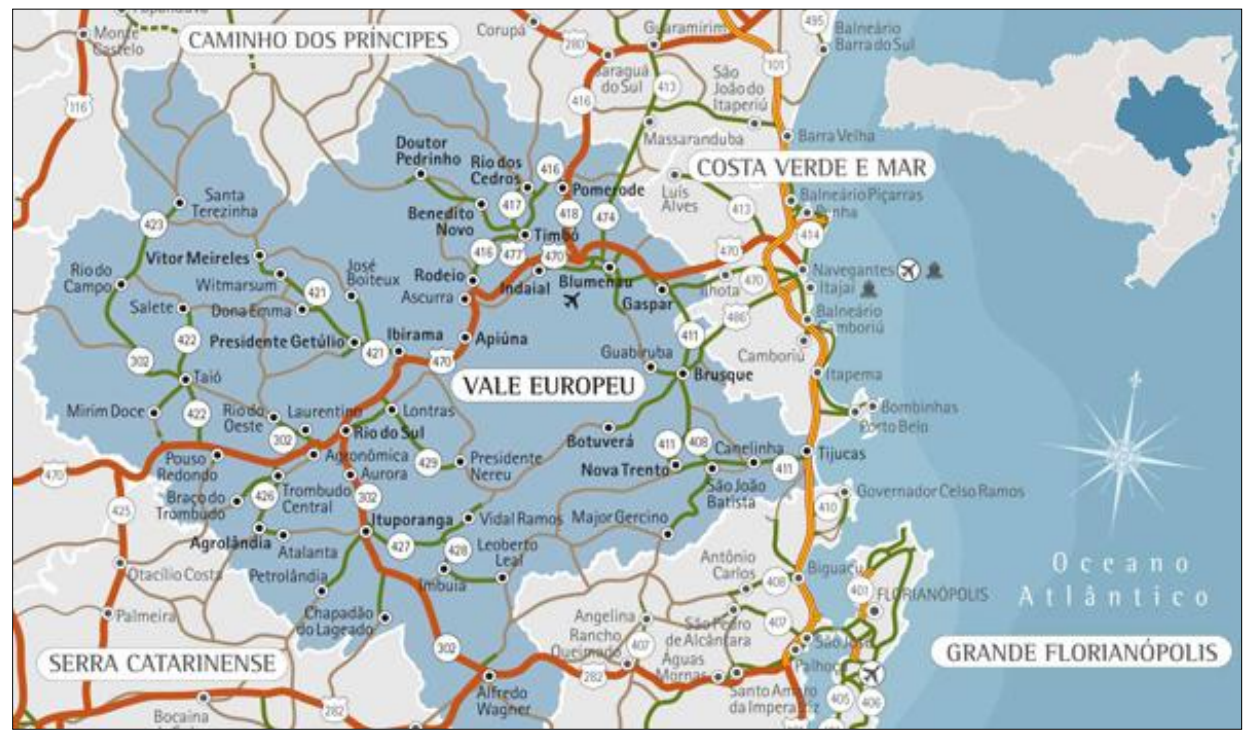

Vigolo é um bairro de Nova Trento. Esta cidade possui um pouco mais de 12 mil habitantes, está localizado aproximadamente 80 quilômetros da capital do Estado, Florianópolis, e a 65 do Balneário de Camboriú. Referência do Turismo religioso em Santa Catarina. Nova Trento é hoje Capital Catarinense do Turismo Religioso, conforme lei Estadual no. 15184 01/06/2010. Cidade aconchegante une o poder da fé com as atrações culturais italianas e as belezas naturais. Possui dois santuários religiosos: Santa Paulina, conhecido mundialmente e Nossa Senhora do Bom Socorro, localizado a 525 metros de altitude, em área de preservação e rara beleza natural. Nova Trento foi colonizada por imigrantes italianos, oriundos do Trentino Alto Agide, norte da Itália, em 1875. Ainda hoje a cidade exibe com orgulho os traços da colonização italiana, presente em seus pratos típicos servidos diariamente nos restaurantes e pousadas. Grupos folclóricos de dança e canto complementam este cenário: eles trazem as características do Norte italiano e, ainda, o dialeto trentino praticado há mais de cem anos. Outra característica desta italianidade é o plantio da uva e a fabricação de sucos e vinhos. Diversas vinícolas mantêm as tradições de seus antepassados. Não é raro encontrar vinhedos e culturas preservadas desde a época da colonização. Entre estradas sinuosas e morros que lembram as montanhas do Trentino/Itália, Nova Trento apresenta também inúmeros córregos, nascentes e cascatas, cenários perfeitos para a prática do ecoturismo e do turismo rural, que aos poucos despontam na região. Mas é da fé que Nova Trento faz o seu maior patrimônio. Além dos dois Santuários, Nova Trento possui mais de 30 igrejas e capelas, distribuídas ao longo das localidades e bairros. Simplesmente um lugar pra 
meditar, percorrer caminhos de fé, renascer e ser feliz, em meio a natureza, onde viveu a primeira Santa do Brasil $\left.\right|^{3}$.

Afirma Z. Rosendahl (COLOCAR NO PADRÃO ABNT) que:

Atualmente, o território, impregnado de significados, símbolos e imagens constitui um dado segmento do espaço - via de regra delimitado - que resulta da apropriação e do controle por parte de determinado agente social, um grupo humano, uma empresa ou uma instituição. Na realidade, o território é um importante instrumento de existência e da reprodução do agente social que o criou e o controla.

Em Vigolo, encontramos um território impregnado de sentidos, símbolos e imagens motivados pela vida heróica da Madre Paulina, administrados pela Congregação das Irmãzinhas da Imaculada Conceição e pela Igreja Católica. Sua vida atualiza diversos aspectos da vida de santos.

Madre Paulina, de alguma forma, retoma o paradigma de santidade vivido por tantos santos e beatos. Viveu sua infância e adolescência, marcadas pelo trabalho, sacrifício e pela oração; órfã que passa a cuidar de seus irmãos, sensível à dor dos outros passa a cuidar de uma cancerosa, dialoga com a Virgem Maria e sofre incompreensões dentro da Igreja, é exilada, foi vitima de doença incurável que a tornou cega e em vida passou a ter a fama de santa. Neste sentido, gostaríamos de destacar alguns santos, muito venerados no Brasil e Itália, que possivelmente viveram as virtudes evangélicas também vividas por Madre Paulina: São Francisco de Assis que pautou sua vida no cuidado dos doentes, especialmente, leprosos e mendigos. De Santa Teresinha, temos o modelo de uma religiosa, exemplo de oração e amor à Igreja; é fácil constatar este amor missionário em Madre Paulina tendo em vista que a Congregação se encontra presente em todos os Continentes. Soma-se a isso a imagem de uma criança chamada Bernadete "que manteve diálogos com a virgem Maria em Lourdes", que podem ser comparados aos sonhos de Madre Paulina com Maria. Outro elemento decisivo que na formação da áurea de santidade é a capacidade de Madre Paulina em agregar moças para o cuidado dos doentes. Esta incitativa a leva a fundar uma comunidade religiosa a exemplos de tantos santos.

3. Cf. Folder Nova Trento, um pedaço da Itália na Terra Santa, Associação Neotrintina do Turismo, Nova Trento. 
Sua vida é repetida reiterada vezes, como forma de divulgar as qualidades da Santa e ao mesmo tempo a importância de se visitar os lugares onde Madre Paulina viveu.

O paradigma religioso de santidade se repete de alguma forma na vida de Amábile. Vejamos: os familiares de Amábile Lucia Visintainer deixam a Itália em busca de dias melhores num vilarejo de imigrantes, denominado Vigolo, município de Nova Trento. A Família de Amábile era extremamente religiosa. Assim, trouxeram para o Brasil não apenas a experiência no cultivo da lavoura, mas também a fidelidade da fé. Para receber a eucaristia, Amábile e sua inseparável amiga Virginia Nicolodi, iam duas vezes por semana a Nova Trento, andando 12 km de ida e volta, percurso este que elas faziam rezando o terço. Em 1882, quando tinha 15 anos, foi convidada pelo Padre Augusto Servanzi, para juntamente com Virginia, ministrar catequese, limpar a Capela São Jorge e cuidar de pessoas doentes. Aos 22 anos, Amábile fica órfã de mãe; assume a função de dona-de-casa, cuida do pai, até este contrair novas núpcias, e dos irmãos. Em 1890, o pai de Amábile se casa novamente. Desta forma ela fica livre para se dedicar inteiramente à vida religiosa. Nesta ocasião Amábile e Virginia passaram a cuidar de uma cancerosa. Esta foi a inspiração para fazer um "hospitalzinho", para nele abrigar os doentes. Após a morte da cancerosa Ângela Viviani, elas permaneceram no casebre cuidando de outros doentes, onde nasceu a Congregação das Irmãzinhas da Imaculada Conceição, em 1890. As primeiras Irmãzinhas eram enfermeiras, faziam os serviços domésticos e ainda trabalhavam como meeiras em roças e na indústria caseira de seda. Aos 07 de dezembro de 1895, a pequena comunidade recebe aprovação eclesiástica, nascendo desta forma oficialmente a Congregação das Irmãzinhas da Imaculada Conceição. Amábile, juntamente com outras jovens da Congregação fazem os votos religiosos. Nesta data ela recebe o nome de Irmã Paulina do Coração Agonizante de Jesus.

Em 1898, Amábile relata seus 3 diálogos com nossa Senhora de Lourdes durante seus sonhos,em noites consecutivas, nos quais a Virgem Ihe dá uma missão, na segunda noite:

Amábile é meu ardente desejo que comeces uma obra: trabalharás pela salvação de minhas filhas. A jovem lhe responde: "Mas como fazer isso minha Mãe? Não tenho meios, sou tão miserável, ignorante..." Assim, acorda... e na terceira noite dá sua resposta: "Servir-vos Minha querida Mãe... sou uma pobre criatura, mas para satisfazer o vosso desejo, prometo me esforçar o máximo que eu puder!”4 (COLOCAR NO PADRÃO ABNT)

4. Cf. GESIEL, Júnior. Madre Paulina - Uma Santa Passou por Avaré: (2002). 
Em 1909, Madre Paulina sofre perseguições dentro da própria Igreja. Dom Duarte Leopoldo e Silva, Arcebispo de São Paulo, para onde ela fora transferida, a destituiu do cargo de Superiora Geral.

Estou pronta para entregar a Congregação para a nova Superiora, e desejo ficar na congregação, em qualquer oficio, até a morte, sob obediência de qualquer Superiora. Meu único desejo é que a obra da Congregação continue para que Jesus Cristo seja conhecido e amado por todos. ${ }^{5}$

Neste mesmo ano, aos 44 anos, Madre Paulina recebe o exílio e é enviada para Bragança Paulista. Primeiramente vai trabalhar na Santa Casa e depois no Asilo São Vicente. Ali trabalhou na limpeza, lavava e consertava roupas dos asilados. Madre Paulina era diabética. Teve que amputar um dedo e, posteriormente o referido braço, em consequência de uma gangrena.

Deus me pediu o dedo, depois o braço. Mas por que negar se sou toda dele? Estou devolvendo aquilo que ele me deu... Que o nome Dele seja louvado em todas as partes, por todas as pessoas e em todos os momentos. ${ }^{6}$

A partir de agosto de 1940, Madre Paulina foi ficando cada vez mais doente; e devido a complicações do diabetes ficou cega. Passou os últimos meses de sua vida cega, vindo a falecer em 9 de julho de 1942, aos 76 anos. A fama da religiosa e de suas companheiras cresceu por toda a região e sua fundadora logo foi chamada de "Santa de Vigolo".

Em 18 de outubro de 1991, na cidade de Florianópolis (SC) - Brasil, Madre Paulina foi Beatificada pelo então Papa João Paulo II, que Ihe concedeu o titulo de "Bem-Aventurada" e passou a ser invocada pelos cristãos como "Bem-Aventurada Madre Paulina, rogai por nós!" No dia 19 de maio de 2002, foi canonizada, no Vaticano, pelo mesmo Papa João Paulo II, que the concedeu o titulo de "Santa Paulina", após a comprovação pela Santa Sé de 02 milagres recebidos por fieis, que invocaram a sua intercessão para serem curados. Estes dois momentos contribuíram sobremaneira para o reconhecimento das virtudes heroica e cristãs de madre Paulina. Uma espécie de alvará para cultuar publicamente a referida santa. ${ }^{7}$

Santa Paulina é invocada principalmente pelos doentes com câncer, pelas parturientes e pelas mães que pedem cura para seus filhos doentes. A história de Amábile (Madre Paulina)
5. Cf. idem.
6. Cf. idem.
7. Cf. idem 
tem traços semelhantes a tantas histórias de santos, a tal ponto que desencadeia a memória ou a recordação de vidas de beatos e santos reconhecidos pela Igreja.

Estes elementos expostos nos ajudam a compreender a formação da religiosidade popular em torno de Amábile. Ela passa a ser vista pela comunidade católica de Vigolo e redondezas como alguém "diferente", isto é, santa, virtuosa e humana. Suas experiências nos reportam a prática de Jesus. A vida e obra de Madre Paulina extrapola o espaço da vila para se tornar atração estadual, nacional e continental.

A criação de novos territórios, bem como a fragmentação ou a fusão de outros, envolve inúmeras localizações regionais, nacionais e internacionais, à semelhança do papel exercido pelas grandes corporações. ${ }^{8}$

Após sua morte, a vila de Vigolo vai se tornando um lugar de peregrinações; fieis de todas as partes da América latina visitam Vigolo com a esperança de receberem graças e bênçãos especiais por sua intercessão.

Importante salientar que a trajetória de vida de Madre Paulina vai criando uma atmosfera diferenciada em Vigolo que passa a ser um lugar de peregrinações e turismo religioso. Os visitantes desejam ver de forma concreta os lugares onde ela viveu, cuidou dos enfermos e onde ela fundou sua congregação religiosa. Desta forma o espaço é construído a partir de uma motivação religiosa. As construções têm o objetivo de ser uma linguagem que recordam a vida da santa e de sua obra. E toda a estrutura urbana de Vigolo e Nova Trento passa a responder as expectativas dos romeiros que desejam ver as "marcas" da santa. $\mathrm{Na}$ realidade, há uma via de mão dupla: de um lado responder às expectativas dos fieis e, de outro, acrescentar progressivamente outras formas econômicas de dinamizar e atrair o turismo religioso. A linguagem da vila Vigolo tem uma semântica comum, refletir no espaço a obra de Santa Paulina, a partir do conhecimento de sua história.

\section{Geografia e teologia: a construção de um novo lugar}

2.1. Um dos aspectos mais relevantes do período atual vivido pela Geografia Humanista é o progressivo envolvimento e interesse de uma parcela significativa de geógrafos no esforço de aprofundar o processo de sua renovação teórica e de afirmá-la como ciência social moderna, incluindo o estudo das mais diversas manifestações da religiosidade. Em outros

8. CORREA, R.L. Trajetórias geográficas. Rio de Janeiro: Bertrand Brasil, 1997. 
termos, a Geografia passa por um momento histórico de grande busca de identificação no conjunto das ciências sociais. Esta busca tem sido marcada, em boa parte, por uma grande abertura dos geógrafos à investigação teórico-metodológica, influenciada pelo positivismo, entre a geografia e as demais ciências.

A religião, por outro lado, sempre foi parte integrante da vida do homem, como se fosse uma necessidade sua para entender a vida. Ambas, geografia e religião, se encontram através da dimensão espacial, uma porque analisa o espaço, a outra porque como fenômeno cultural ocorre espacialmente. ${ }^{9}$

Por outro lado, a geografia e a religião são duas práticas sociais. O ser humano sempre refletiu a geografia como vivência do lugar, ainda que de forma descritiva, como também, a religião sempre fez parte integrante da vida do ser humano por meio da busca de sentido do seu fazer, manifestada pelas inúmeras questões que se colocam em toda a história da humanidade sobre a sua própria existência. De outro lado, a experiência religiosa dos indivíduos ou grupos representa ponto central em várias ciências humanísticas.

Essa preocupação aparece na psicologia da religião, tanto na abordagem freudiana, em que se considera o caráter ilusório da religião, como na junguiana, na qual se valorizam os sonhos, fantasias, mitos e seus símbolos. Aparece também na sociologia, através do pensamento de autores clássicos como Emile Durkheim10 e Max Weber11. Na antropologia, a temática em pauta emerge nas teorias da religião dominadas pelo enfoque evolutivo e pelo desejo de explicar a origem das religiões ${ }^{12}$.

É notório que a geografia cultural já traçou um itinerário significativo a partir da Escola de Berkeley que teve como característica, em meados dos anos 1920, reagir ao determinismo ambiental. No outro polo da reflexão, há um esforço de se mostrar certo determinismo cultural (religioso) sobre o espaço. Determinadas cidades, regiões, rios, montanhas e ambientes uma vez marcados pelo significado religioso tornam-se símbolos de fé e passam a ter uma semântica diferenciada do habitual. Fica neles acoplada a marca do sagrado com um forte poder de atração dos fieis. Apenas para ilustrar, mencionamos alguns exemplos onde encontramos a atividade do imaginário religioso.

\footnotetext{
${ }^{9}$ ROSENDAHL, Z. Geografia e Religião: uma proposta. In: Espaço e cultura, no 1. Rio de Janeiro NEPEC, 1965, p.45.

10. Cf. DURKHEIM, Emile. Les formes Elementaires de La Vie Religieuse. Paris: Presses Universitaires de France, 1968.

11. Cf. WEBER, Max. Economia y Sociedad Mexico: Fondo de cultura Econômica, 1964.

12. ROSENDAHL, Z. Geografia e Religião: uma proposta. In: Espaço e cultura, no 1. Rio de Janeiro NEPEC, 1965.
} 
A paisagem geográfica é o resultado de mudanças realizadas na natureza. Essas mudanças possuem uma linguagem simbólica, pois toda transformação é consequência de um conjunto de traços culturais que se expressa a partir da linguagem. Neste sentido, o espaço geográfico é o depositário de um conjunto de "signos" culturais, também chamados de símbolos que provocam a decodificação. Este trabalho de fruição do espaço realizado pelo decodificador leva o leitor a perceber os mais diferentes estilos, épocas, símbolos, materiais que aparentemente estão "mortos". O espaço não é neutro, ele traz sempre uma carga cultural, política, econômica, dentre outras, que aparece na construção de um lugar. As motivações religiosas na construção de um espaço trazem a marca da fé impregnada da religiosidade popular. Neste sentido, a vida de uma pessoa, seu processo de conversão ou de busca de Deus vai criando um "mito" capaz de atrair milhares de pessoas. Neste "mito" estão presente as graças que poderão ser recebidas pela intercessão de um santo, como também milagres ou contato direto com Deus. Aqui não podemos esquecer todas as formas de promessas, doações e dízimos.

A complexidade da produção do espaço tem exigido uma crescente socialização do trabalho intelectual, o que não significa apenas uma prática interdisciplinar no âmbito do trabalho acadêmico, mas um vasto campo de estudos sobre a sociedade. Nenhuma ciência em particular pode reivindicar exclusividade de estudo sobre este ou aquele processo social específico, tal o grau de interação entre os complexos problemas da sociedade contemporânea e mesmo das teorias que têm sido desenvolvidas para interpretá-los. A realidade ultrapassa as teorias para tratar de compreender ou explicar essa realidade.

A geografia já não é a mesma. No campo religioso, a ideologia tem um papel cada vez mais amplo na interpretação do espaço, como afirma Milton Santos:

Em nossos dias, a ideologia vê aumentado o seu papel na interpretação do espaço, pelo fato de os objetos serem planejados e construídos com o objetivo de aparentar uma significação que realmente não têm. Tal significação é, muitas vezes, um resultado da preocupação com interesses de ordem internacional. Daí a importância do estudo das relações internacionais. E é para separar o significado assim outorgado ao objeto do seu valor real que a contribuição da semiologia surge como importante. ${ }^{13}$

13. SANTOS, Milton - Por uma geografia nova. Hucitec, 3a Edição. São Paulo, 1986, p. 108. 
Outro aspecto relevante é reafirmar que o espaço geográfico "aparece" através da linguagem, ou por meio de "signos". Para Charles Sanders Peirce, estudioso e fundador da ciência da linguagem, signo "é algo que, sob certo aspecto ou de algum modo, representa alguma coisa para alguém". ${ }^{14}$

A ideologia religiosa se manifesta no espaço por meio de construções próprias como templos, grutas, campanários, pregações, sacramentalização, via sacra, lugares por onde passou a santa. Todas estas linguagens passam a ter significado para as pessoas de fé. A Igreja Católica, certamente aprecia a divulgação destes "mitos" com apelos à realidade, uma vez que são fontes econômicas e pedagogia de atração de muitos fieis.

Vigolo é um bom exemplo da diversidade histórica. De um lado se encontram os museus refletindo a história da colonização italiana em Nova Trento. De outro as contínuas construções de hotéis, mosteiros, novo templo, para atender a demando os peregrinos.

Tendo-se em conta esta conceituação, afirma Z. Rosendahl,

As temáticas da religião, da percepção ambiental, da identidade espacial e interpretação de textos (literatura, música, pintura e cinema) estão entre outras temáticas que emergiram ou foram retomadas. 0 espaço urbano passa a ser objeto de interesse para os geógrafos culturais. ${ }^{15}$

A nova linguagem da vila Vigolo, lugar do comércio e do turismo religioso

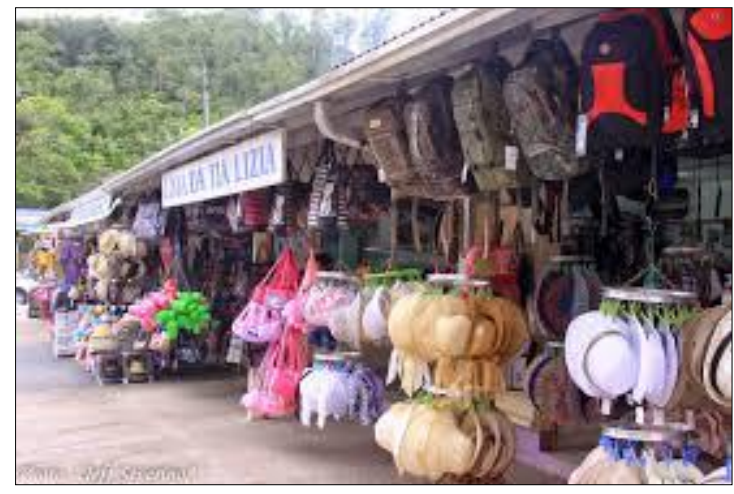

Hildebert Isnard no seu texto "O Espaço Geográfico" (PADRÃO ABNT) fala desse "como campo de representações simbólicas, rico em signos que cumprem a função de expressarem

14. PIERCE, Charles S. - Semiótica e Filosofia, São Paulo: EDUSP, 1978, p. 94.

15. ROSENTHAL Z. e CORREA, Roberto L. (org), Manifestações da Cultura no Espaço. Rio de Janeiro: Ed. UERJ, 1999, p. 53. 
a estruturas sociais em suas mais diversas dimensões".${ }^{16}$ Assim sendo, as formas espaciais, por meio das quais o simbolismo ganha materialidade, constituem meios através dos quais a cultura é modelada.

\section{Vigolo fala por meio dos seus símbolos.}

É de fundamental importância para entabular um diálogo com Vigolo, fruir de sua linguagem. Entendemos que Vigolo é um mosaico de tempos, trabalho humano, estilos, de urbano-rural. Provocativo, Vigolo se insinua, pede reações, arranca o observador atento da passividade. Ao mesmo tempo em que provoca, ele se esconde; traz a marca do misterioso, do lugar da santa.

A aldeia Vigolo é uma permanente energia passada e presente, profana e religiosa, signos que convivem no mesmo espaço. Há uma relação de sentido entre templos, monumentos de Madre Paulina, ruas, praças, hotéis, casebre, comércio, museus, trânsito, enfim entre fixos e fluxos. Todos estes signos sempre dizem alguma coisa. É um feixe de códigos variados, é uma pluralidade de manifestações, adormecidos ou não, à espera de um fiel. Em outros termos, Vigolo nos oferece um imenso conjunto de códigos "engessados", à espera da decodificação, o despertar de sentido.

A chave de leitura da energia de signos de Vigolo é a vida de Madre Paulina, seu nascimento, sua vinda para o Brasil, enfim sua história marcada pela fé e vivência de cristianismo.

Henri Lefebvre ao falar da compreensão do texto urbano se utiliza das ciências da linguagem.

A projeção do global para a prática e para o plano específico da cidade só foi realizada através das mediações. Mediação ela própria, a cidade foi o local, o produto das mediações, o terreno de suas atividades, o objetivo de suas proposições. Processos globais, relações gerais só se inscreviam no texto urbano quando transcritos por ideologias, interpretados por tendências e estratégias políticas. Donde a dificuldade, sobre a qual convém agora insistir, de conceber a cidade como um sistema semântico, semiótico ou semiológico, a partir da linguística, da linguagem urbana ou da realidade urbana considerada como um conjunto de signos. No decorrer de sua projeção pra um nível específico, o código geral da sociedade se modifica; o código específico do urbano é uma mediação desse código

16. CORREA, R.L. A dimensão cultural do espaço: alguns temas. In. Espaço e cultura, 1995. Rio de Janeiro: Ed. UERJ, 1995, p. 10. 
geral, uma versão, uma tradução incompreensíveis sem o original e o originário, Sim, lê-se a cidade porque ela se escreve, porque ela foi uma escrita. ${ }^{17}$

Seguindo a linha de pensamento de Lefebre não é suficiente examinar o texto desligado do contexto para apreender a cidade. O contexto nos oferece os fundamentos dos interpretantes sígnicos. A este respeito o autor afirma,

Escrever sobre esta escrita ou sobre essa linguagem, elaborar a metalinguagem da cidade não é conhecer a cidade e o urbano. O contexto, aquilo que está sob o texto a ser decifrado (a vida quotidiana, as relações imediatas, o inconsciente do "urbano, aquilo que não se diz mais e que se escreve menos ainda, aquilo que se esconde nos espaços habitados - a vida sexual e familiar - e que não se manifesta mais nos tête-à-tête), aquilo que está acima desse texto urbano (as instituições, as ideologias) isso não pode ser esquecida na decifração." ${ }^{18}$

O turismo religioso da Arquidiocese de Florianópolis descreve o potencial turístico de Nova

Trento, colocando em destaque os lugares por onde passou e viveu Madre Paulina.

O principal atrativo turístico de Nova Trento é Madre paulina. Milhares de romeiros visitam a localidade de Vígolo para louvar e glorificar a Deus, agradecendo-o pelas graças e benefícios físicos e espirituais recebidos pela intercessão de Madre Paulina. O complexo religioso compreende a Igreja de Vigolo, o cenário vivo narrando a vida de Madre Paulina, a réplica do casebre onde a Madre viveu, a Casa da Congregação das Irmãzinhas da Imaculada Conceição, a estátua de Madre paulina, o marco jubilar pela passagem do milênio e o monumento construído no local onde ficava a casa dos pais de Madre Paulina. ${ }^{19}$

Neste sentido é de grande ilustração a fala de Milton Santos:

O espaço que nos interessa é o espaço humano, ou espaço social, que contém ou é contido por todos esses múltiplos de espaço. Esses são objetos de disciplinas particulares, como a semiótica, a escultura, a pintura, o urbanismo, a física, a astronomia etc., que se definem de uma forma particular. ${ }^{20}$

Nem tudo o que a ideologia religiosa proporciona como manifestação espacial tem o mesmo significado para todas as pessoas. As diferentes ideologias carregam também as marcas da diversidade e de suas expressões. Aqui cabe recordar o que afirma Milton Santos sobre o espaço entendido como

17. LEFEBVRE, Henri. O direito à cidade. São Paulo: Editora Documentos Ltda., 1969, p.55

18. Idem, p. 55

19. Cf. ZANATTA, K. L. Madre Paulina, roteiros de fé em Santa Catarina. Florianópolis: Mares do Sul. 2001.

20. SANTOS, Milton - Por uma geografia nova, p. 120. 
[...] um conjunto de relações realizadas através de funções e de formas que se apresentam como testemunho de uma história escrita por processos do passado e do presente. Isto é, o espaço se define como um conjunto de formas representativas de relações sociais do passado e do presente e por uma estrutura representada por relações sociais que estão acontecendo diante dos nossos olhos e que se manifestam através de processos e funções ${ }^{21}$.

A vida de Madre Paulina lançou sobre seus objetos e lugares onde viveu e trabalhou uma nova semântica, que passam a ser visitados pelos fieis, como a igreja Nossa Senhora de Lourdes construída pelos imigrantes em 1876, inclusive por Napoleão Visintainer, pai da Santa; no interior da igreja se encontram uma imagem de Madre Paulina e um osso do seu braço; também muito procurado é o local onde Amábile viveu com os pais entre 1876 e 1890; no local da casa paterna foram pintados painéis contando os principais fatos da vida de Amábile; muito visitada é a réplica do casebre utilizado por Amábile Lucia Visintainer e sua amiga Virginia Nicolodi para tratar de uma doente de câncer; da mesma forma a casa da fundação da Congregação das Irmãzinhas da Imaculada Conceição em 1890; também atrai a atenção dos fieis a capelinha do santuário onde Madre Paulina tratou Angela Lucia Viviani, doente de câncer. Um local de especial atenção é a fonte de água anexa a Igreja, onde os fieis bebem a água "milagrosa" e enchem os vasilhames para levar aos doentes, parentes e amigos.

O território religioso de Vigolo, suas novas exigências. Uma nova linguagem urbana.

O território religioso, entendido como reflexo do espaço vivido no cotidiano da fé contribui para fortalecer as relações e os fluxos que se instauram pouco a pouco no espaço e que dão origem a uma independência religiosa e a um sentimento de pertencimento ao grupo religioso envolvido. Vê-se, portanto, que território e identidade estão indissoluvelmente ligados. Lembremos que o território favorece o exercício da fé e da identidade religiosa do devoto. A religião só se mantém se sua territorialidade for preservada. ${ }^{22}$

21. Idem. Por uma geografia nova, p. 122.

22. ROSENDAHL, Zeny e CORREA, R. L. (org). Espaço e Cultura: Pluralidade temática. Rio de Janeiro: Ed. UERJ, p. 57. 


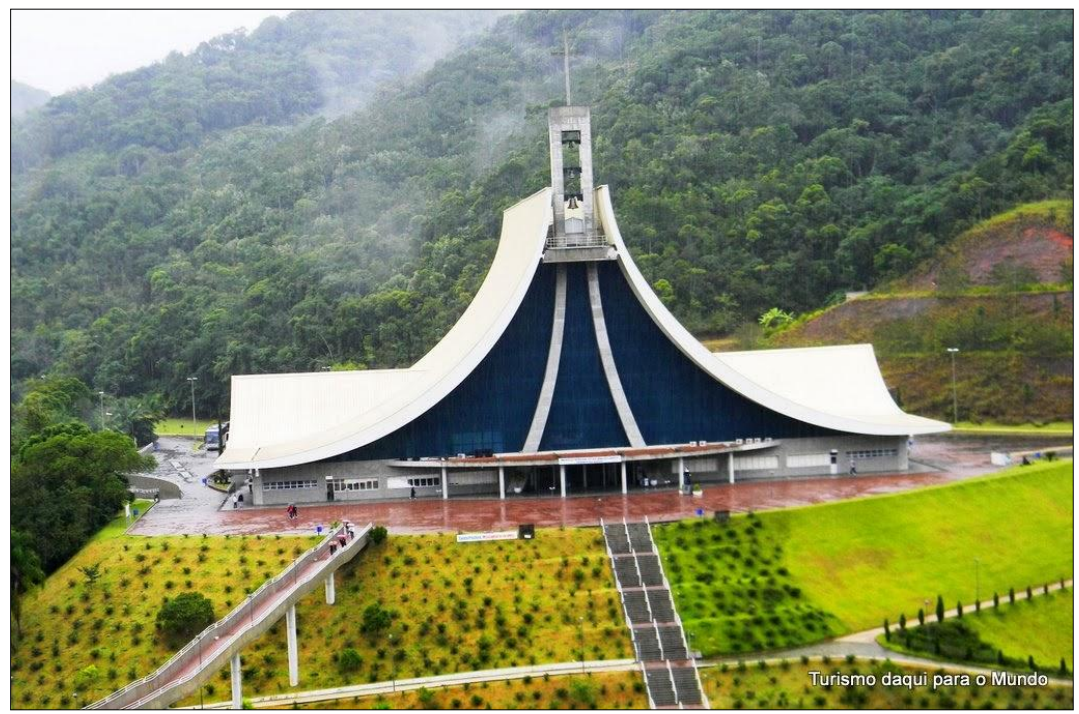

O grande fluxo de fieis motivados pela vida de Madre Paulina suas intercessões e milagres passaram a exigir de Vigolo uma nova territorialidade, uma nova linguagem simbólica. A nova territorialidade religiosa representa o conjunto de práticas desenvolvidas por instituições ou grupos religiosos no sentido de coordenar pessoas e objetos num dado território. É uma forma de manter e legitimar a fé. É exemplificativo olhar para o território de Vigolo a fim de examinar o surgimento de diversos sinais de mudança a partir das motivações religiosas.

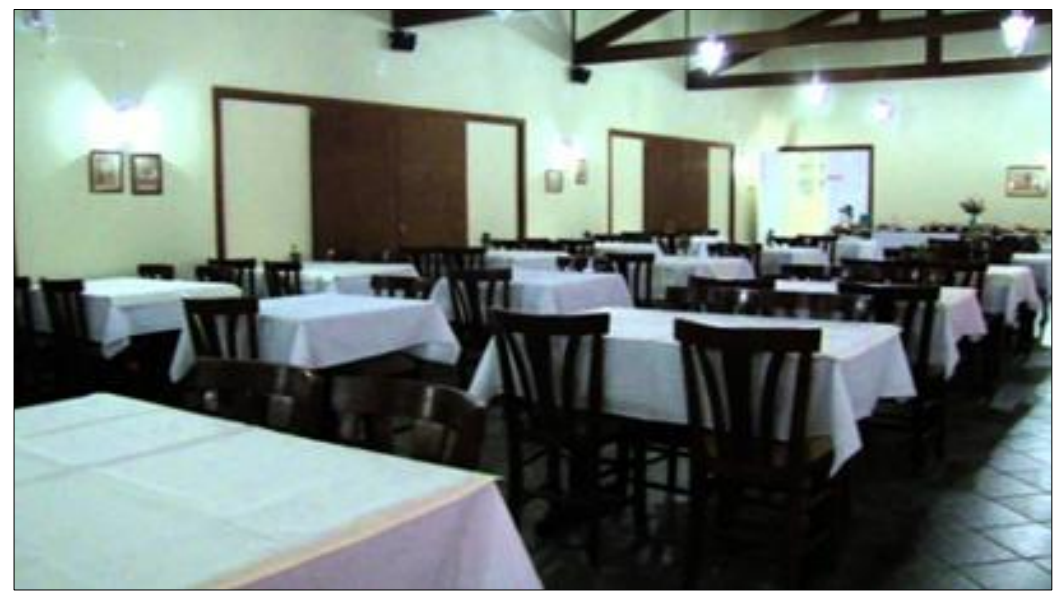

Foram construídos novos hotéis, restaurantes, hospedarias como Mosteiro Park Hotel, Pousada Portal do Vigolo, Natalina (eventos e Hospedaria), Pousada Museu e Arte, Pousada e Cantina Trento, Sitio Nona Lurdes, Restaurante Trevo, etc. A Prefeitura de Nova Trento tratou de instalar farmácia e postos de saúde para dar atendimento e pronto socorro aos fiéis; Delegacia de Policia para garantir a ordem social; Planejamento urbano o que incluiu a organização e novo direcionamento do trânsito, construção e melhoria de estradas de 
acesso de nova Trento a Vigolo, ponto de Táxi em Vigolo; instalação de um Centro de Turismo. Com a ajuda da Congregação das Irmãzinhas surgiram novos espaços de oração e de turismo, como o Parque Colina Bondinhos Aéreos; Mirante, Vista do Centro; Monte Baron; Oratório do Calvário; Museu Cultura Italiana; construção de um novo Santuário Santa Paulina, com a capacidade de abrigar mais de 2000 fiéis; ao lado disso, notamos a instalação de dezenas de lojas para a venda de artigos religiosos, como imagens, terços, santinhos, livros de piedade, história de Madre Paulina e de outros santos. Passou também a funcionar um Velário, Museu de Cera Sacro e loja de artigos religiosos em todos os espaços ao redor do complexo: Igreja, Convento, Hospitalzinho. Mereceu também um cuidado especial a recuperação da Casa Paterna de Santa Paulina: é o primeiro monumento antes de chegar ao Santuário, é composto de painéis em azulejo, com algumas cenas da vida de Santa Paulina em Vigolo e os sonhos que ela teve com Nossa Senhora. Museu Colonial - é um museu de utensílios que Santa Paulina e também os imigrantes italianos usavam em suas casas. Ele está em frente à Praça da Igreja Nossa Senhora de Lourdes. Museu da Seda - réplica da Fábrica de Seda que Santa Paulina, com suas companheiras, construíram e trabalharam, encontrando neste empreendimento, condições para dar emprego a muitas pessoas e para manter as Irmãzinhas da Congregação. Esta fábrica sustentou a Obra por mais de 20 anos. Construção da "Nova Casa das Graças" - um espaço de 373 metros quadrados construído para acolher os objetos da beatificação, da canonização e as promessas dos peregrinos; lugar das lembranças, do louvor, da gratidão, do testemunho de quem experimentou a grandeza e o amor de nosso Deus pela fé e perseverança, por meio de uma graça.

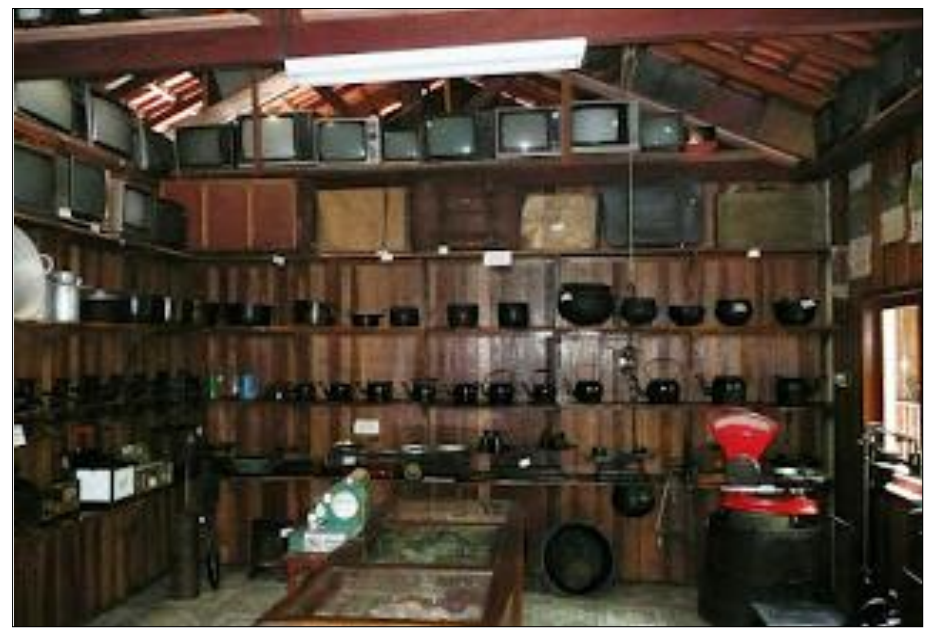



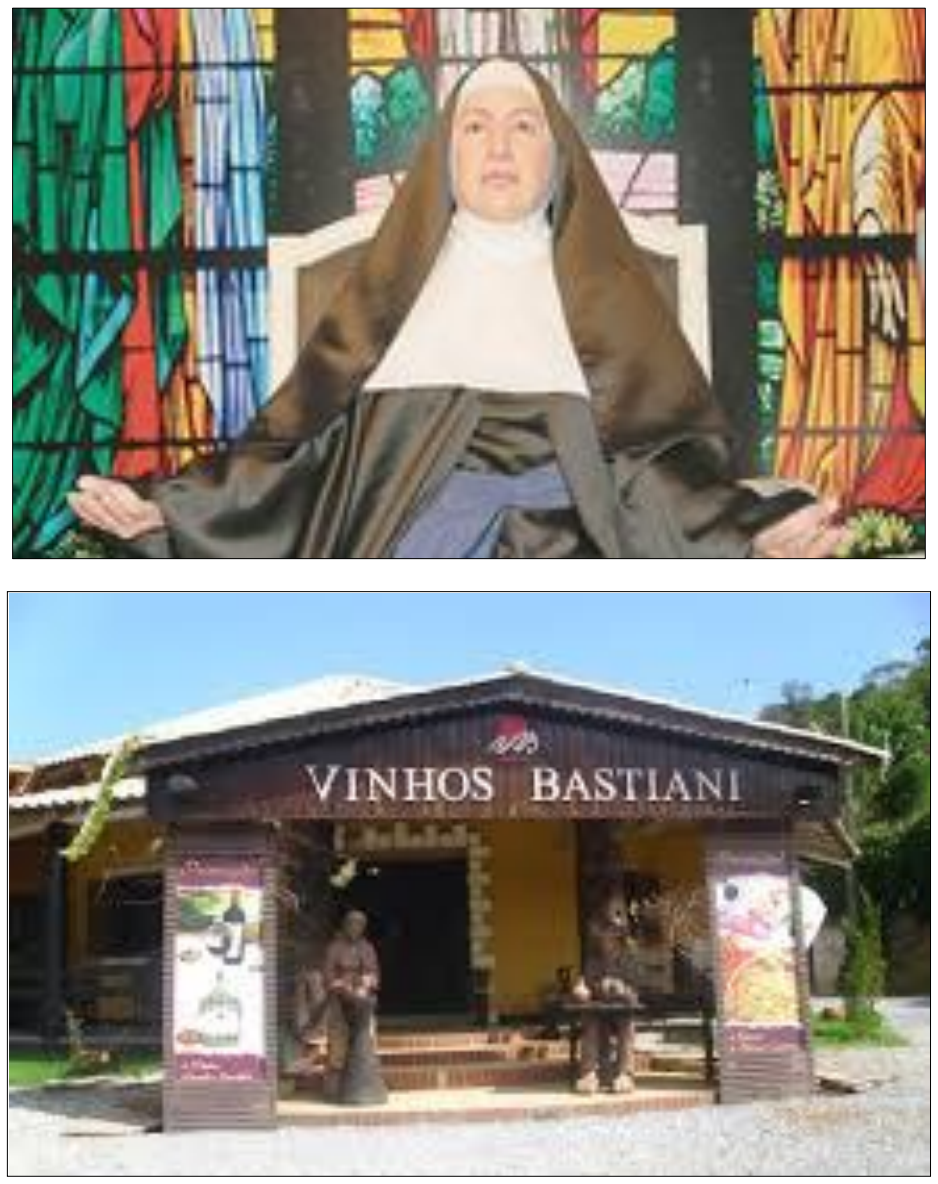

Com o turismo religioso, o comércio de Vigolo recebeu um novo incremento. Foram instaladas muitas adegas que se localizam as margens da estrada que dá acesso a Vigolo: Adega Bastiani; La Torre do Vinho Vô Luiz; Vinhos Girola. Varias fábricas de vinho passaram a funcionar. Da mesma forma, vendas de produtos coloniais, como queijos, salames, mel, macarrão, bolachas, cucas, feijão dentre outros produtos. Ex. Empório Colonial; Armazém dos Sabores; Fabrica da Laticios Tentrolat; na época da safra de uva, muitas vendas são improvisadas à beira do caminho.

Foram criados novos postos de trabalho. Nas décadas de 70 e 80 a maioria dos jovens de Nota Trento e Vigolo partiu para cidades maiores, como Blumenau, Florianópolis, Brusque, Curitiba, Comburiu, Porto Belo e Itapema em busca de emprego. A partir da beatificação e canonização de Madre Paulina, na década de 90, muitos postos de trabalho foram criados para servir a demanda de romeiros. As famílias de operários passaram a residir em Nova Trento e Vigolo, o que exigiu a construção de novas escolas primárias e secundárias para atender a demanda dos filhos dos novos moradores. Nova Trento e Vigolo passaram a atrair 
também pessoas de outros estados brasileiros com o objetivo de trabalhar ou de arriscar seu próprio negócio.

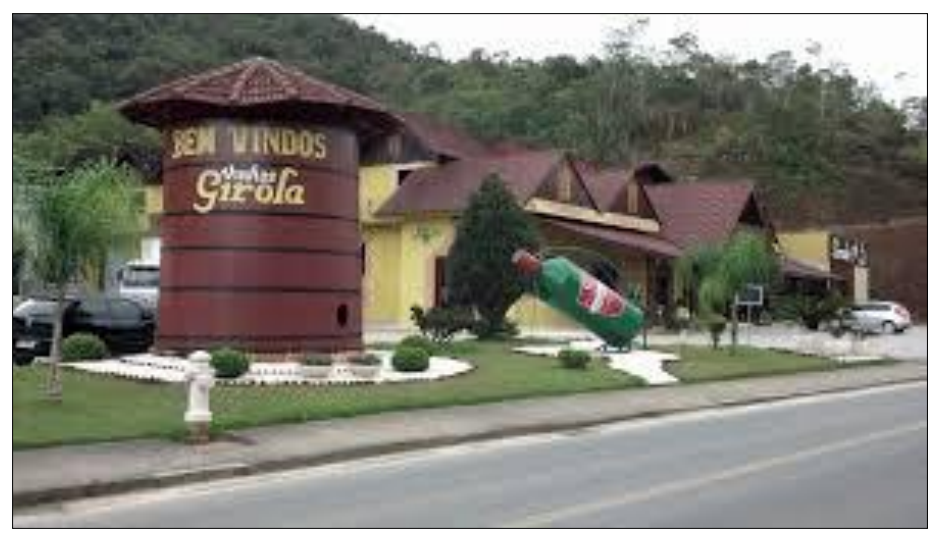

O turismo religioso produz seu marketing relacionado com hotéis, casas de comércio, de retiro, enfim, todas as formas de ofertas de serviços aos romeiros se utilizam de folders, panfletos, placas, luminosos, dentre outros para realizar sua propaganda. Aqui também se encontra a dinamização de gráficas na produção deste material, e de novos postos de trabalho.

O turismo religioso trouxe junto a especulação imobiliária. As propriedades de colonos que há décadas adquiriam uma propriedade para o cultivo da família, plantação de uva, milho e mandioca, criação de suínos e vacas leiteiras, agora preferem vender esta mesma propriedade em pequenos lotes. Desta forma o espaço urbano vai crescendo em Vigolo em detrimento das propriedades coloniais extensas de décadas anteriores.

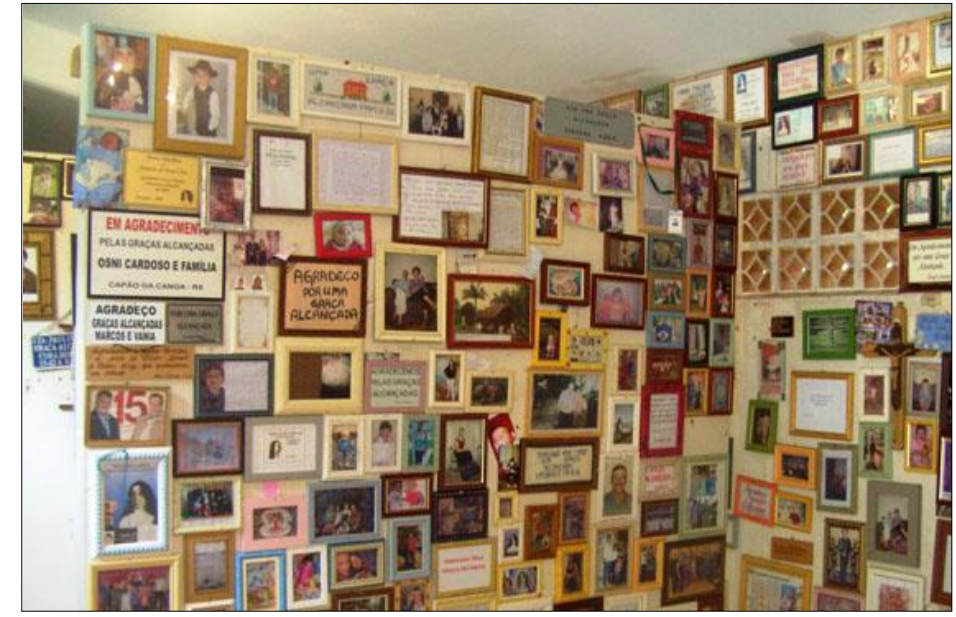

Sala dos milagres. Devoção e amor por Santa Paulina. 


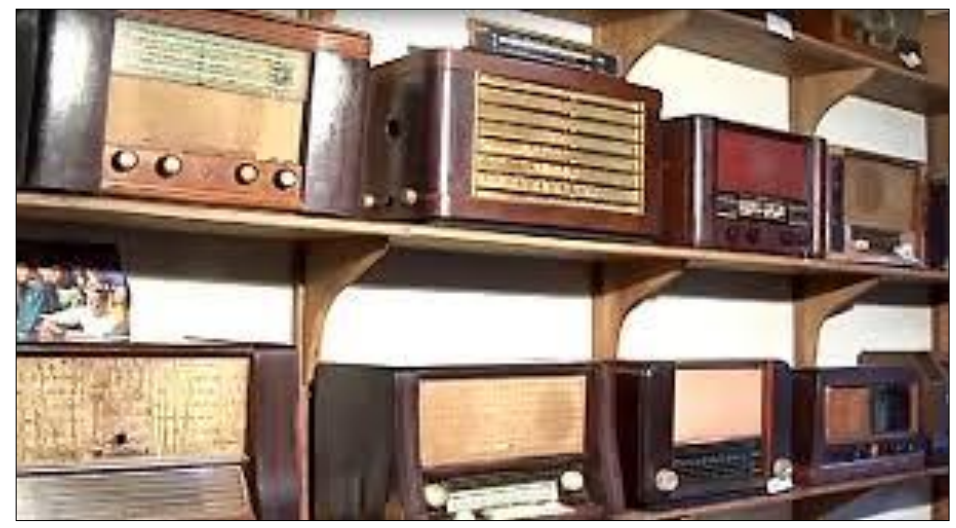

Utensílios domésticos e televisores antigos.
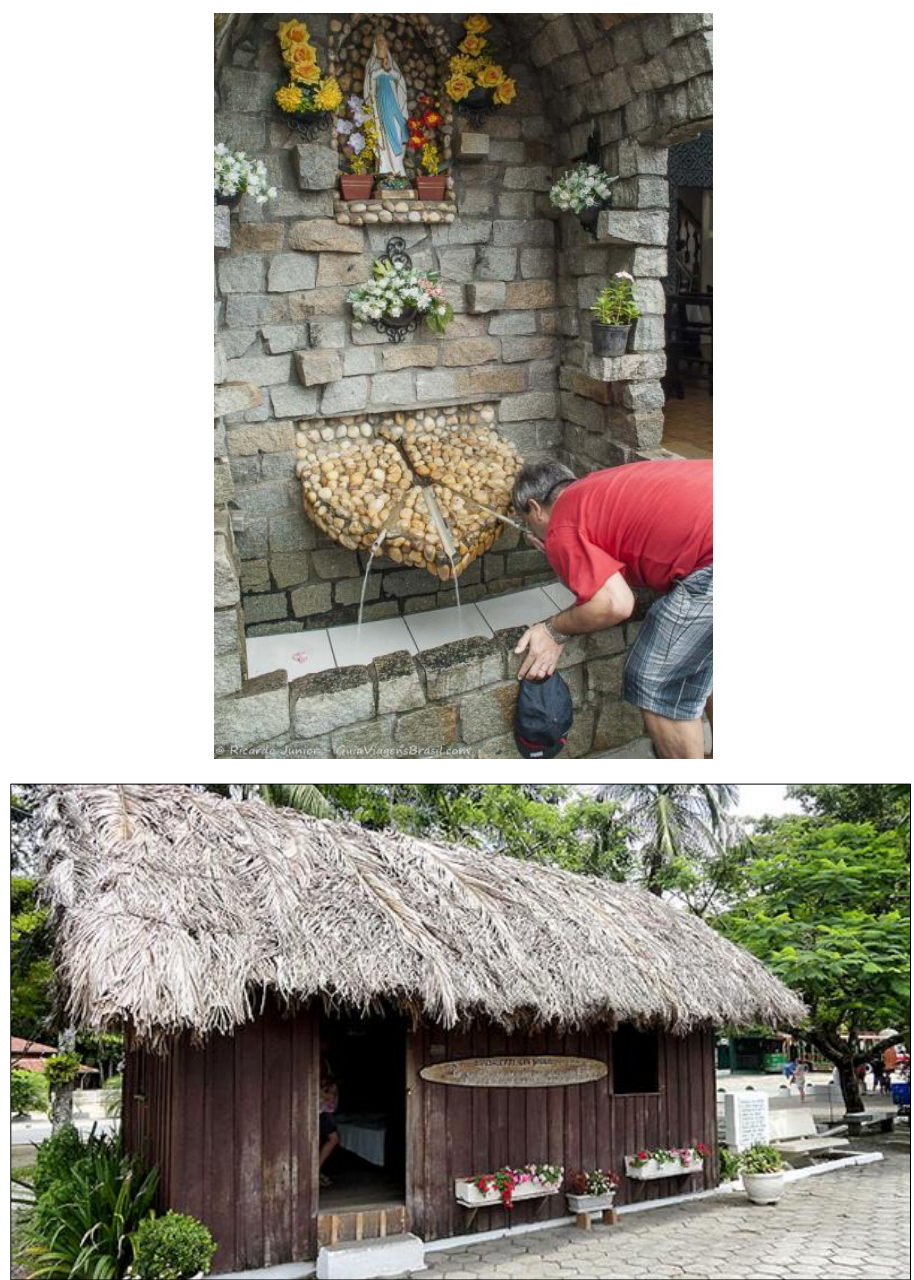


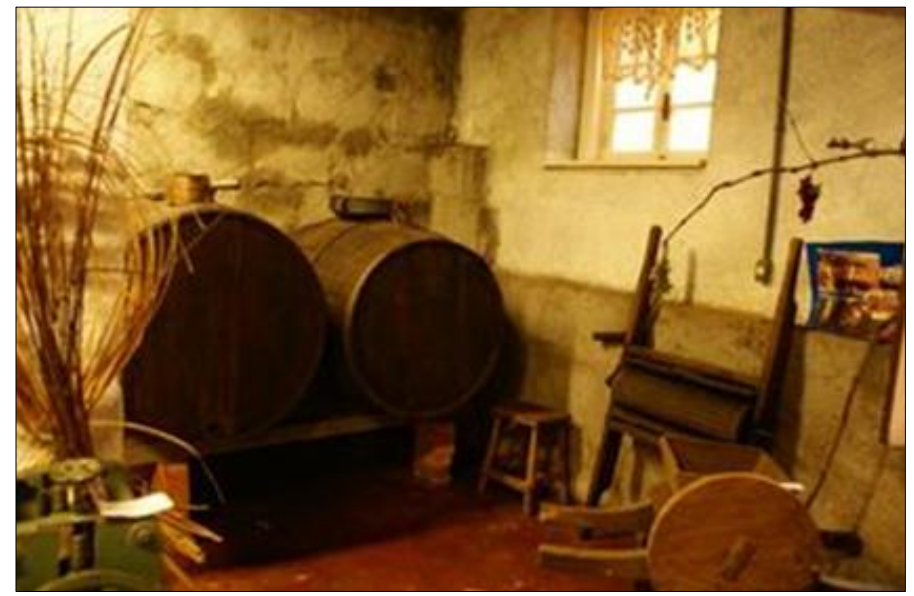

Réplica da casa da Leprosa que recebeu os cuidados de Madre Santa Paulina. Um dos lugares de maior devoção. Ao lado, os fieis bebem da água com esperança de receberem graças. Local de grande visitação.

\section{CONSIDERAÇÕES FINAIS}

Geografia e teologia dialogam na reorganização do novo espaço em Vigolo, Nova Trento. A cultura religiosa, tendo como cenário a vida de Madre Paulina, foi se firmando e realizando uma nova reorganização espacial. A fim de acolher as novas exigências do despertar da fé em Santa Paulina, muitas transformações ocorreram nos lugares onde viveu, trabalhou e fundou sua comunidade religiosa. Está história demonstra que nenhuma ideologia religiosa é neutra na sua expressão espacial. Os reflexos aparecem não só na construção de um lugar de veneração, mas também aparecem nas relações de turismo, comércio e sociais. Isto é sustentado por uma forte organização marqueteira, tendo como objetivo atrair pessoas para o lugar de veneração.

Este trabalho refletiu o espaço humano ou espaço social, no qual encontramos a dimensão religiosa como motivação principal. A religiosidade pode despertar as pessoas para a criação de um novo espaço. A religião pode suscitar novas relações sociais, inclusive, relações de trabalho, de comércio, de lazer e de piedade. Atualmente, as religiões tem se servido deste enfoque para propiciar muito mais o crescimento econômico do que crescimento interior das pessoas. De fato, as novas religiões pentecostais avaliam o aspecto religioso pelo viés do econômico.

A análise que fizemos neste estudo nos mostrou que a história de uma pessoa, marcada pelo paradigma da santidade pode levar uma Instituição ou uma Congregação e suas atividades a realizar novas formas e novas funções para os novos consumidores. 
Em Vigolo, reina a atmosfera da "curiosidade e do mistério", da promessa e busca de milagres pela intercessão da Madre Paulina. Na criação deste mistério, encontramos o papel da Instituição. Primeiro pela divulgação da vida de Amábile, atribuindo-Ihe características de santidade, pela sua Congregação e, posteriormente, a beatificação e canonização ocasião em que aparece a voz da autoridade máxima da Igreja Católica.

Muitos lugares, altamente significantes para certos indivíduos e grupos, têm pouca notoriedade visual. São conhecimentos emocionalmente e não por meio do olho crítico ou da mente. [...] Uma peça de escultura pode encarnar uma humanidade e ser o centro do seu próprio mundo. Apesar de uma estátua ser um objeto em nosso campo de percepção, parece criar seu próprio espaço. ${ }^{23}$

A partir destes elementos, a religiosidade popular de Vigolo passa a ter como centro a vida e obra de Madre Paulina, e sua santificação Ihe garante o estatuto para realizar um espaço da Vila Vigolo com tudo o que for necessário para despertar ainda mais a devoção a primeira Santa Brasileira.

\section{BIBLIOGRAFIA}

AZEVEDO, A. F.; PIMENTA, J.R. e SARMENTO, j. (org.). Ensaios de Geografia Cultural. Porto: Figueirinhas, 2006.

BAUMAN, Z. Confiança e medo na cidade. (trad. Eliana Aguiar). Rio de Janeiro: Zahar, 2009.

BARBOSA, Fidelis Dalcin. Madre Paulina, a coloninha. São Paulo: Edições Loyola, 1988.

CADORIN, Célia B. Ser para os outros. São Paulo: Edições Loyola, 2001.

CASTRO, I. E. , GOMES, Paulo Cesar e CORREA, R.C. (org). Geografia: Conceitos e Temas. Rio de Janeiro: Bertrand Brasil, 2012.

CHIQUIM, Carlos Alberto. Pastoral do Turismo. Curitiba: Kyrios Editora, 2013.

DARDEL, Eric. O homem e a terra: natureza da realidade geográfica. (trad. Werther Holzer). São Paulo: Perspectiva, 2001.

ELIADE, M. O sagrado e o profano. São Paulo: Martins Fontes, 2001.

HOLZER, W.; JUNIOR, E. M.; OLIVEIRA, L. (org.). Qual o espaço do lugar? São Paulo: Perspectiva, 2012.

LEFEBVRE, H. O direito à cidade. São Paulo: Editores Documentos LTDA. 1968.

LORENZI, Guido. Madre Paulina, entre carisma e obediência. São Paulo: Edições Loyola, 2001.

${ }^{23}$ TUAN, Yi-Fu. Espaço e lugar: a perspectiva da experiência. Londrina: Eduel, 2013, p. 200. 
ROSENDAHL, Z. "Espaço, cultura e religião: dimensões de análise". In CORREA, R. L. E ROSENDAHAL, Z. (orgs.). Introdução à geografia cultural. Ride Janeiro: Bertrand Brasil, 2003, PP. 187-224.

"Espaço, política e religião". In CORREA R. L. e ROSENDAHL, Z. (org.). Religião, identidade e território. Rio de Janeiro: Ed. UERJ, 2001, PP. 9-39.

Espaço e Cultura: pluralidade temática. (org). Rio de Janeiro: Ed. UERJ, 2008.

Espaço e religião: uma abordagem geográfica. Rio de Janeiro: Ed. UERJ, 1996.

Espaço e cultura: uma abordagem cultural. Rio de Janeiro: Ed. UERJ, 1995.

. Hierópolis: o sagrado e o urbano. Rio de janeiro: Ed. UERJ, 1999.

ROSENDAHL, Z e CORREA, R. L. (org.). Geografia: temas sobre cultura e espaço. Rio de Janeiro: Ed. UERJ, 2005.

SANTOS, Milton. Por uma geografia nova. 3a edição. São Paulo: Hucitec, 1986, PP. 97-122.

TUAN, Yi-Fu. Espaço e lugar: a perspectiva da experiência. Londrina: Eduel, 2013.

Topofilia: um estudo da percepção, atitudes e valores do meio ambiente. Londrina: Eduel, 2012.

Artigo submetido em

$07 / 10 / 2014$

Artigo aceito em 